\title{
Asthma hat bei Landeiern keine Chance
}

\author{
Die Amischen in den USA betreiben traditionelle Landwirtschaft mit Tieren. Damit schützen sie \\ ihre Kinder offenbar vor Asthma, wie ein Vergleich mit den technikverliebten Hutterern nahelegt.
}

\begin{abstract}
Die Autoren untersuchten zwei isoliert lebende, Landwirtschaft betreibende US-Populationen: die Amischen und die Hutterer. Erstere setzen auf eine Arbeitsweise ohne moderne Maschinen, letztere auf Industriemethoden. Um die Asthma-Prävalenz zu bestimmten, wurde das Blut von jeweils 30 Kindern auf Allergiezellen und Zytokine getestet, außerdem die Reaktionen von Leukozyten auf Stimuli wie Lipopolysaccharide.

Bei den Amischen fand sich kein Kind mit Asthma, bei den Hutterer sechs. Die Amischen wiesen niedrigere IgE-Werte und höhere Leukozytenzah-
\end{abstract}

len auf. Genexpressionsprofile der Leukozyten ergaben, dass unterschiedliche Gene hochreguliert waren. Bei den Amischen wurden Gene überexprimiert, die sowohl TNF als auch IRF-7 beeinflussen - zwei Schlüsselproteine für die Immunantwort auf mikrobielle Stimuli.

Untersuchungen des Hausstaubs ergaben sehr viel höhere Mengen an Endotoxinen bei den Amischen. Um die Auswirkungen auf die Entwicklung allergischer Entzündungen zu testen, exponierten die Forscher junge Mäuse über längere Zeit gegenüber dem Hausstaub. Der Ovalbumin-Test ergab signifikante
Vorteile für Tiere, die den Hausstaub der Amischen eingeatmet hatten.

- Stein MM et al. Innate Immunity and Asthma Risk in Amish and Hutterite Farm Children. N Engl J Med. 2016;375:411-21

\section{KOMMENTAR}

Die Arbeit bestätigt die durch Studien bereits belegte Hygienetheorie. Erstmals wird aber wirklich gezeigt, dass Endotoxine in der Umwelt die Zellen im Blut und die Genexpression bei Kindern beeinflussen, und dass die Asthma-Entwicklung auch von der Zusammensetzung von Inhalationssubstanzen abhängt.

Prof. Dr. med. J. Bargon

\section{Cholesterinester-Kristalle bei Mangel an lysosomaler saurer Lipase}

Bei einer 18-jährigen Frau persistierten nach einer WindpockenInfektion erhöhte Transaminasespiegel. Bei der körperlichen Untersuchung fielen ein niedriger BMI von $18 \mathrm{~kg} / \mathrm{m}^{2}$, eine $4 \mathrm{~cm}$ unter dem Rippenbogen tastbare Leber und eine Splenomegalie auf. Der untere Milzrand reichte bis in die linke Fossa iliaca. Im Labor ergaben sich folgende Werte: ALAT $133 \mathrm{U} / \mathrm{l}$, AST $63 \mathrm{U} / \mathrm{l}$, Gesamtcholesterin 366 mg/dl (LDL 296 mg/dl, HDL 29 mg/dl). Serologische Untersuchungen auf eine Virushepatitis, Autoimmunhepatitis oder einen Morbus Wilson waren unauffällig.

Die CT des Abdomens ergab eine Hepatosplenomegalie und Zeichen einer Steatose der Leber (Abb. A). In einer Leberbiopsie fand sich eine ausgeprägte, diffuse, mikrovesikuläre Verfettung der Leberzellen und eine Lipidanreicherung in den Kupfferschen Sternzellen (Abb. B). In den letzteren zeigten sich außerdem doppelbrechende Cholesterinkristalle im polarisierten Licht (Abb. C) - ein Befund, der pathognomonisch ist für einen Mangel an lysosomaler saurer Lipase (LAL). Die genetische Testung ergab eine heterozygote Mutation im LIPA-Gen.

Der LAL-Mangel ist eine seltene, autosomal rezessiv vererbte Speichererkrankung. Anreicherungen von Cholesterinestern und Triglyceriden in den Makrophagen sind typisch. Unspezifische klinische Zeichen sind gastrointestinale Symptome und Gewichtsver-
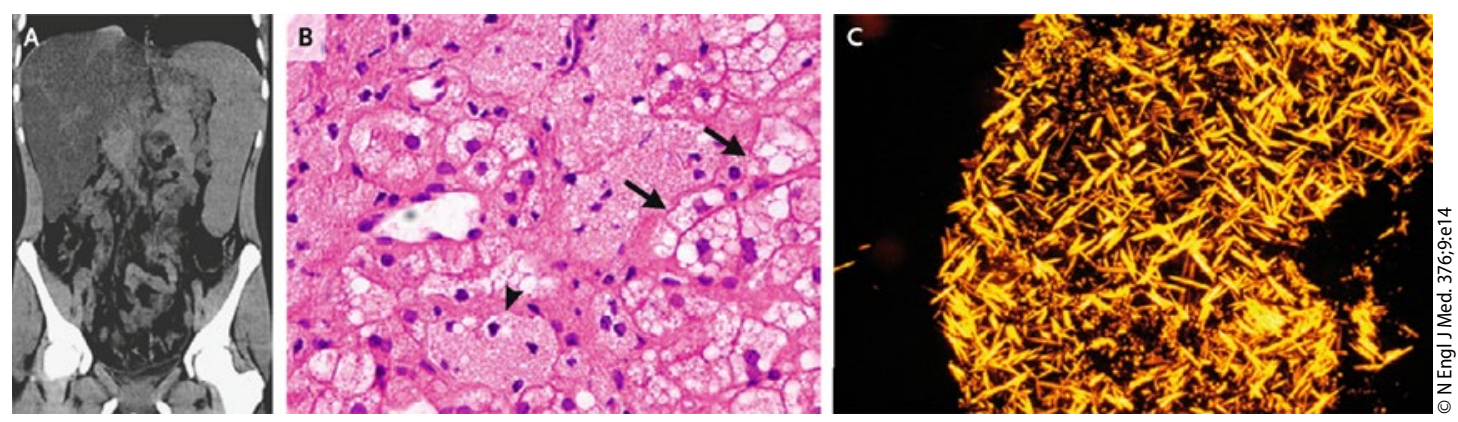

lust. Beide Symptome lenken oft ab und verzögern die Diagnose. Seit Kurzem gibt es eine Enzym-Ersatztherapie mit Sebelipase-alpha, die auch hier erfolgreich zum Einsatz kam.

Prof. Dr. med. H. S. FüeßI

- Ivashkin V, Zharkova M (zhrakovamaria@mail.ru).Cholesterylester crystals in lysosomal acid lipase defi-

A: Hepatosplenomegalie. B: Verfettung der Leberzellen (Pfeile), Lipidanreicherung in den Kupfferschen Sternzellen (Spitze). C: Cholesterinkristalle in den Kupfferschen Sternzellen. 